\title{
ABOUT THE MODEL OF HIGHER EDUCATION - UNIVERSITY TRADITION, CHANGES, PROBLEMS AND SUGGESTIONS OF SOLUTIONS
}

\author{
Tadeush Levovitski \\ Doctor Habilitatus in Humanities, Professor \\ Honorable rector of the Higher Teacher Education School of the Polish Teachers' Union \\ Foreign member of the National Academy of Pedagogical Sciences of Ukraine \\ Higher Teacher Education School of the Polish Teachers' Union, Poland \\ rektor@wsp.edu.pl
}

\section{ABSTRACT}

Thinking about higher education the author referred to university traditions. Social needs changes and development of universities have influenced the higher education model. Higher education has become differentiated and various types of schools of university level have to fulfil different functions. These transformations are not reflected in the overall approach to educational issues and they give rise to numerous problems. All this demands a new strategy in school education at the post-secondary level and a new approach to the higher education model. What becomes an important message of this study is drawing attention to the chances resulting from treating education as social good and from creating such a model of school education in which university level schools (fulfilling various dominating functions) support one another in their activity and development.

Keywords: differentiated higher education model; educational transformations; functions of universities; higher education; university.

\section{INTRODUCTION}

Higher education - its level, fulfilled functions, the network of schools and their availability, as well as many other issues related to the activities of universities and relations with almost all the areas of life - largely determines the opportunities for development of individuals and societies, as well as social capital and a quality of life. This view seems to be widely accepted, and its legitimacy is confirmed by the experience of the countries and societies showing concern for higher education development, quality of education and the impact of education on different areas of people's lives. The greatest benefits - the tangible ones, for example economic or business, but also those that are difficult to measure but still very important, manifested in the development of people, personalities, cultural - are usually referred to rich societies on a high level of civilization. The sources of their success and power, both ancient and modern, were and are various - often coming from the colonial conquest, plunder, exploitation. Today they are building their power via the care about science and education conducive to the progress of civilization, new technologies which are friendly to people. We treat this as the almost obvious phenomenon in terms of rich societies.

The modern world, however, provides opportunities for development and success not only to wealthy societies, but, as it seems, in an unprecedented 
dimension - to the societies whose lives were not successful and which had little opportunity to compete with powers. One of the opportunities is already involved in emerging of a global knowledge society. In our region in the world - connected with the region of North America and increasingly binding economic ties with giants of Asia - the knowledge society is no longer a vision plotted by futurologists but in many ways it is a reality. The participation in this particular society does not have to determine their reserves of raw materials, competitive world-scale economy, capital (although certainly all this would be helpful), and can decide and as it probably will happen - will determine the knowledge acquired, created and used by the community and society. And in this regard, education should play an important role, and particularly education at the highest levels. Higher education and science, as many things seem to indicate to this, in so far unknown extent, affects the fitness of populations and its place and function in the world. This is the aforesaid opportunity for those who do not belong to the powers. This is a chance for our society.

The awareness of this civilization advancement possibility and also the condition of success in the contemporary and future functioning seems to be quite big in Poland. Given the statements of politicians, representatives of the state administration and corporate scientists, as well as the voices of journalists and the work of many authors from university environments, it might be considered that the importance of higher education and science is appreciated and that these cases are treated with due care. From time to time there erupts "noise in the media", arises criticism of various phenomena in higher education, sometimes citing the examples of foreign models, and provided are the suggestions for improvements. The official strategy for the development of education and science has been established; various groups of people presented their "strategies".

Of course, it is good that such actions are taken. But it is hard to resist the impression that many of the actions there are ad hoc and deprived of a holistic view of higher education - views and proposals for improving the actual state of affairs. The cited examples will remain hereinafter. Here it should be noted that in our country the threads of strategic thinking about education and about the model (models) of higher education have been lost for years. Instead such way of thinking can be observed in the various reports and studies abroad - especially from the years of development of education in the industrialized countries (Kupishevich, 1978; 1982). What's more - in Poland several years ago numerous works on models of higher education in the world were created (studies prepared in Institute of Science Policy, Technical Progress and Higher Education - now that are probably available in the Warsaw University Library). In the 80 s of the last century - on the threshold of change in the political system - there were available the studies concerning model solutions embracing higher education. In some of them were foreseen the events and processes that occurred in the 90 s and later. Numerous expert evaluations, the "model" works and others - that can be used in creating a new model of education - had no echo. The examples can be the studies devoted to open universities (Regulska, 1990). To date, no Open University has been established in Poland, although it may have been established more than twenty years ago. The similar situation arose with studies regarding a model of higher education diversification (Levovitski, 1985).

Underestimation of the output devoted to models of higher school (and higher education), and attempts to create proposals based on individual and sometimes accidentally invoked, foreign examples, which have dominated in our country since 
the 90 s of the last century in various endeavours changing higher education, it makes it impossible to read in these doings a clear thinking determining education strategy and model of education. Slogans and declarations of struggle for the quality of education at a higher level - combined with propagated, loud media, but very partial solutions - do not form a coherent strategy and embrace only a part of education. Some solutions, which also will be discussed later in this text, rather forge attention to the quality of education, than actually serve as a care about its quality. In this situation justified are the attempts to recall some of the proposals now forgotten, and, I think, possible to be used in the conditions of modern education. It is worth reminding about a series of works on the model of education. These works illustrate the holistic approach to the covered topics; facilitate the noticing and understanding of at least some important problems that can be the basis of new overall shots. One should also look at the way the development of higher education, tradition and the changes which have occurred within about a millennium and which are approaching today. It may turn out helpful in the search for a model of higher education of the XXI century, due to the aspirations of our society. Helpful in considering the matters mentioned below may also be questions and answers or hints showing some solutions that go beyond the accepted patterns and established practices.

The issues brought up further largely relate to the higher education in the whole. Differentiation of education and the conditions under which it operates, lead, however, to the fact that a part of exemplification and proposals will be interesting primarily for theoreticians and practitioners, and maybe, also for politicians and state administration responsible for that part of education which prepares pedagogues (pedagogical faculties of various universities) and teachers (in different schools and in different fields of study). In a good education of pedagogues and teachers there is still a great chance to become a society of knowledge.

Due to the multiplicity of issues, as I think, important in the discussions of education, it is necessary to make a choice among these issues, and each of them is presented by me in a summary form. They reveal notable threads in thinking and actions in favour of education. Let this rather unusual form serve for reflection and possible changes in the perception of issues and problems - than comprehensive discussion of particular issues.

\section{TRADITION AS ONE OF THE SOURCES OF THINKING ABOUT HIGHER EDUCATION}

In the European tradition higher education has been associated with universities for centuries. Discussions about higher schools were mainly disputes about the model or models of universities. Universities were typical, and in fact, the only ones - apart from a few examples of different academies and "closed" schools, that intended to prepare a selected group of future managers of public life, or, for example, they prepared the most educated strata of the clergy - by higher school.

In ancient cultures knowledge was already observed as a major factor of gaining and exercising power. Similar situation was observed in Europe during the establishment of the first universities. The formation of the Italian, French, English universities, and also the oldest universities in our part of the continent in Prague and Krakow, was usually accompanied by the struggle for the following: 
whether they should serve the state authority, ecclesiastical authority or to be as much as possible - independent and serve the development and dissemination of knowledge. Decisions depended on many factors - the founders, strength and wisdom as determiners of the social and political life, but also on the procedures of university communities. All this meant that there were different ways of development and various fates of particular universities. Also, accepted were different ways to organize, manage, and transmit internal social order, relationships between teachers and students. The seemingly uniform world of universities in many ways turned out to be varied (Eg. Bashkiewich, 1997; Kot, 1996; Voloshyn, 1964). The transmission of the tradition, however, carries an important message, and this message is the common aspiration of universities to exploration of the world, to enrichment of knowledge and its dissemination, preserving the memory of the cultural heritage, creation and care of the highest intellectual and moral values. About universities - as one can judge, modelled on the old, classic predecessors - it is written loftily that they "constitute a specific and unique type of temples, appointed to carry the light of pure knowledge to the humanity and enrich learning, and to produce the highest intellectual and moral values. They have a certain sacrum in themselves, just as objects of religious worship, and their respectability and dignity are sanctified by are charitable activities that have been serving the humanity for already nearly nine centuries. This activity bears all the hallmarks of a mission" (Marek, 1995: p. 19).

The transmitted image of universities includes the pursuit of academic communities for the truth, dealing with all areas of knowledge and the special community ties which are expressed in determining universitas magistrorum et scholarum - a community of teachers and students. It is thanks to this community special conditions for conducting research, search for truth and education exist. One of the basic functions of universities - except the research and transfer of cultural heritage - it is training itself, in which both professors and students are active agents.

An often emphasized feature of the old school was their autonomy. One way to avoid dependence on secular or ecclesiastical power was setting up of the universities under the initiative of students and other people. With time the ranges of independence developed differently.

The general idea of the university and the basic features define the contemporary idea of these universities. And even if the descriptions of the ancient universities are idealized, they still carry the message of an educational establishment where research is carried out, takes place a process of unhindered training and personality development, knowledge is created and disseminated as the most important value, truth and goodness are appreciated. An important message is also a model of a community of scientific men.

This image of the remembered tradition described in brief remains a source of ideas about the most ancient and - as it is often considered - the best model of higher education, which has clearly defined basic objectives and deals with - as far as time and possibilities allow - all the areas and disciplines of knowledge.

\section{SPECIALIZATION AND DIFFERENTIATION OF A HIGHER SCHOOL MODEL}

A few centuries of functioning of universities led to the recognition of these educational establishments for university knowledge. A university is an institution 
of representatives of all sciences and for the development of these sciences. But as I said - the model of university education in many respects was uniform only apparently. Understanding of the basic tasks and functions, access to knowledge, program and organizational solutions differed, among others, depending on the fact who exercised custody over the universities: secular / state authorities or church authorities, or private patrons, or finally, as far as possible, independent university communities, local, or some other. Attempts to influence academia were (and still are) understandable, because these environments have become extremely important in shaping views on the organization of social life - they could therefore foster the stability of various ideological systems, social relationships, hierarchy of values, but they could also (and it was often so) threaten the prevailing social order, generate opposition, rebellion, desire for change. All this - we are repeating was reflected in the relations between academia with other communities and made the university model, the model of university education varied already in the Middle Ages. Time brought new reasons for differentiation.

After a few centuries of the activities of universities and the development of science, as well as socio-economic changes in Europe, there arose circumstances even more defining the diversity of the university educational establishments. These changes, the needs of a growing industry and the needs of the state elite, cultural traditions of particular societies led to the fact that in the nineteenth century there was a clear separation of the three common models of universities.

The first of them - most associated with a traditional university, university of science - was based on the assumptions of Humboldt University. Its characteristics are the combination of research with didactics and the focus on multilateral general education.

The second - referring mainly to the English patterns - has become a model of an elite university, educating power elite strata of management. More than other models of the educational establishments, the university served for maintaining of the social structure and strengthening the socio-economic order. Today, we would define this as a focus on reproduction of the social order.

The third model - sometimes associated with French universities - has became a model of a specialized or particular university, oriented to combine theory with practice and - more than any other schools - serving for preparation of students for selected professions. Under this model was formed higher vocational school, caring for the overall development of students, but great care is taken to the expertise and skills in professions performance (including technical occupations) (Levovitski, 1985).

Further specialization, new needs and other considerations led over the years to various types of other higher education institutions hiving off from the universities, taking some of the features of the three models, and the creation of new structures. Thus there were established polytechnics, schools (academies), medical schools and schools of fine arts and others. The XX century, especially the second half of this century, is the time of setting up of a number of specialized, professional education institutions as well as new universities. This diversity of higher education establishments meant that the functions of different types of institutions had to be perceived otherwise than previously. This issue is present in the following sections of this text. It has - as I think - a particular importance in understanding and creating the model (s) of higher education or higher schools. 


\section{TRANSFORMATION OF EDUCATION AND THE TRADITIONAL FUNCTIONS OF HIGHER SCHOOLS}

Education at different levels, and above all education at the university level, remained a good, unattainable for many people for a long time. Especially difficult was the access to higher education. The reasons are well known, so there is no need to recall them.

Until recently, a relatively general formulation of the general duties assigned to education was sufficient. It is widely accepted - and in general shots it is still assumed - that education should, first of all, maintain cultural traditions, share the achievements of previous generations and previous experience, and, secondly, prepare for participation in the social, economic, cultural, scientific and other areas of human functioning (Shchepanski, 1963; 1976).

The recognition of these duties (objectives, tasks, and function) does not explain, however, what is to be transmitted to the legacy of the past, and whether it is necessary or needed for a contemporary man to be able to operate successfully in different areas of life. The matter is complicated by the rapid spread of education at the level of schools that are above secondary education level, and these schools differentiation is already being signalized.

It would be relatively easier to define the basic functions of the university elite - including traditional universities. Despite their differences they served primarily for:

1) maintaining cultural continuity, transfer of scientific achievements and consolidating systems of adopted values and behaviours;

2) development of intellectual skills of the trainees;

3) preparation of the privileged elites - to direct the state administration and the economy, to direct the state institutions;

4) preparation of experts to assist the group in charge of the state ( $\mathrm{I}$ am also writing about this: Levovitski, 1985).

An elite higher education fulfilled its common specific functions relatively well, which were production, transfer and implementation of knowledge (Touraine, 1979).

After World War II democratization of social life took place, and it was accompanied by the "school explosion" (L'Cros, 1961) - first at the level of primary and then secondary education. It also cleared the way for wider access to higher education. Initially, the rapid quantitative growth of higher education took place in the highly industrialized countries. It is worth recalling some of the data. In the mid-60s of the last century - in the academic year 1965-1966 in the countries of the European region (according to UNESCO they are the European countries, USA, Canada and Israel - countries considered to be similar in terms of cultural traditions and socio-economic development) more than 13 million people studied, in the academic year 1971/1972 about 20 million, and in the academic year 1978/1979 - about 26 million, thus more than twice in the academic year 1965-1966.

The enrolment rate in the age group of 20-24 years in the academic year 19651966 was about $22 \%$ in these countries and more than $25 \%$ in $1971 / 1972$, and in 1979 it was around $30 \%$. In most developed countries - including the US on the third level of education already studied more than $50 \%$ of young people of the typical age for higher education (Development de l'education en Europe: analyze statistique, UNESCO 1980). All this meant that thirty years ago, it 
was emphasized that higher education "was transformed definitively from elite institutions (...) in the institution of the mass" (Kupishevich, 1982). The next decades brought further development of higher education.

Since the turn of the state system in Poland in 1989, this development took place in our country too. Let's recall: that year in Poland there were 112 institutions of higher education, in which 78.4 thousand students studied (Statistical Yearbook of the Central Statistical Office, 1992). According to the latest data in the academic year 2010/11 there functioned 460 higher schools and more than 1,841 million students were educated there (Statistical Yearbook of Poland, GUS, 2011). Therefore, during the two decades the number of institutions of higher education increased more than fourfold, and the number of students - almost fivefold. It should be added that during this period the largest number of students educated at higher educational institutions was in the academic year 2005/06 more than 1,953 million students. Gross enrolment ratio increased from 12.9\% in the academic year 1990-1991 to $53.8 \%$ in the academic year 2010/11, the net enrolment rate from $9.8 \%$ in the academic year $1990-1991$ to $40.8 \%$ in the academic year 2010/11 (Higher schools and their finances in 2010, GUS, 2011, p. 26).

In higher education - which should be stressed - there were significant structural changes. In addition to public/state institutions of higher education, private institutions of higher education were created. In 1990, there were 2 nonstate universities and in the academic year 2010/11 - 132 public universities and 328 private universities. In those first studied about $68.5 \%$ of all students, and in the second $-31.5 \%$ of all students (ibid). What's more - some educational institutions conducted studies only at the first level of education. In this situation - caused by the regulations in force - after the two-stage higher education - higher education includes both schools of a similar nature to the old model of university and higher vocational schools.

All this means that the traditional functions of universities are fulfilled only by part of an educational institution (or mainly by part of an educational institution other parts fulfil certain functions, such as creation of knowledge or preparation of elites, rather rarely). Instead, there appeared a need to determine the dominant functions assigned to vocational schools, because these are not established and are generally not able to perform all the typical functions of a university educational establishment.

\section{DIFFERENTIATION OF HIGHER SCHOOLS AND DIFFERENTIATION OF THEIR FUNCTIONS}

Quantitative development of higher education - the process of spontaneous creation of proper academic education under the conditions of rapid growth of social demand for education in universities, but also without adequate attention to the development of teaching staff and infrastructure - pretty quickly it brought a clear differentiation in the level of higher education. The reasons for this variation are well-known, and the plurality were particularly significant feature of staff shortages, shortages of libraries and available sources, the lack of actual supervision of the quality of education. It is worth remembering that, for example, almost five times the increase in the number of students, as it was mentioned previously, was accompanied by the increase in the number of teachers in the years 1990-2010, only slightly more than one and a half times - 
in the academic year. 1990-1991 64454 teachers worked (Higher schools and their finances in 2007), and in the academic year 2010/11 about 103.5 thousand academics - full-time and part-time (Higher schools and their finances in 2010). These data, however, refer to the number of posts, not academics. Since a large group of teachers are employed at more than one position, in fact, the number of teachers has increased relatively little. What's more until recently, some academics were employed in a number ("record holders" in a dozen) of universities, so they were often rather fleeting guests than those involved in the educational process. This phenomenon was (and in part still is) severe in non-public schools, which were and are several times more numerous than the public - currently 328 , and only about $17.3 \%$ of all teachers (ibid) are employed in them. It should be added that private universities educate more than 580.1 thousand students, or more than $31 \%$ of the total number of students (ibid).

The introduction of two-cycle studies - caused in part by exaggerated desire to assimilate higher education system in Poland to the system prevailing in the European Union - became a formal confirmation of diverse universities and the nature and level of education. It was assumed to introduce professional studies (at the I degree) and general theoretical elements (at the II degree). The division into the studies of the I degree - Bachelor - and the II degree - Master - included, among others, education in the field of pedagogy and teachers' training hold in a variety of fields beyond pedagogy.

The recall of these cases (skipping others) illustrates the diversity of higher education institutions. The reflection of this diversity is the functioning of several categories of universities - universities, specialized universities, academies, higher schools (specialized and professional). These education institutions have different fields of education and various privileges (such as to confer titles and academic degrees, professional titles). All this clearly confirms that higher education is internally diverse - and is differentiated in various ways.

This, as it appears, obvious observation, however, rarely finds acceptance in thinking about the functions of higher education, and even more in the consequences of the recognition of universities and their functions diversity. Perhaps this is one of the key issues in determining the model of higher education and conditions for the development and functioning of higher schools. So, it is worthwhile devoting special attention to this particular case.

The traditional functions of universities, which were briefly mentioned in the previous section of this text, today find various details and development. Today's universities are expected to fulfill a variety of new features - in accordance with social needs. In addition to the functions which are generally called research and educational, highlighted is the need to fulfill the following functions: cultural, professional, improvement, retraining, self-development and others - including preparation of scientific personnel, experts, etc.

Universities (and especially large universities having already a rich legacy, good staff) generally perform all these functions. The most important actions still remain in the domain of the research and knowledge creation, transfer of this knowledge and training of scientific personnel, transfer of cultural tradition of the elite and experts training. In these areas revealed are the dominant functions of an education institution. These schools are able to perform many other functions and they fulfill these functions. You can - simplifying - say that they are multifunctional, and even 
in this respect universal. Such perception of universities seems reasonable, although in the second half of the last century began the process of creating environments outside educational establishments (some of the stable - included in the institutional framework, some ad hoc - to perform research tasks) creating new knowledge and new technologies. In the fields of humanities and social sciences primacy in the creation of knowledge, studies and research remains - as before - was in the university environments. Therefore this deals with pedagogical sciences too.

Patchy is the picture of function of specialized universities - technical, medical, of natural sciences and so on. Some of them (for example, medical universities, universities of natural sciences) perform all these functions. A part of them appears in a limited scope to fulfil the functions of knowledge creation, conduct original scientific researches, and to be focused on the functions of teaching and education - and others dealing with general professional and personal development of the taught people. Depending on the educational establishment general vocational or professional educating functions are dominant. As, probably, each education institution, - they also fulfill many other functions - creating culture, expertise, etc. It should be emphasized, first of all, that their dominant functions are different from those in universities of a general type.

Yet another is the image of the dominant functions in the activity of higher vocational schools. They should, first of all, prepare students for undertaking professional tasks. They also often play important environmental functions, cultural and others - which are significant in the local environment. Relatively rarely they undertake authentic, original scientific researches. They are primarily destined to fulfill selected functions. If to some extent they are able to fulfill the functions relevant to university educational institutions, it really testifies to their health and development, and this may augur well for the future. However, the expectations, assigned to them, are connected, first of all, with vocational training.

Summarizing this - as I believe - is an important line which should be emphasized that as far as possible, all the higher schools can perform a set of functions relevant to higher educational establishments - and they often more or less fulfill these functions. Different, however, are the dominant functions of the various categories or types of educational institutions. And this phenomenon is - conditioned, among others, by the capabilities of human resources, tasks of an educational establishment, working conditions, the scale of involvement in solving scientific problems - clearly presented in the activities of the higher schools.

Differentiation of the educational establishments and the scope of their dominant functions should carry certain consequences dealing with legal regulation, tasks, expectations in accordance with individual (types) of schools and their employees. I will refer to this matter later in the text.

Stressing the diversity of higher education institutions and their dominant functions it is necessary to pay attention to another kind of differentiation. Well, it may be a situation of internal differentiation of an educational establishment. Different tasks and functions can be fulfilled (and known are the cases when this happens) by individual units of the same education institution. Some departments or institutes may (for various reasons) fulfill the functions appropriate for universities, other - for general vocational education institution, and others - for vocational schools. Such complex organisms of higher education institutions form a community with specific opportunities for mutual assistance in fulfillment of environmentally-cultural functions. 
And then we deal with, firstly, with a model of differentiated higher education, where education institutions fulfill different ranges of function (including the dominant functions), and, secondly, a model of a internally diverse model of higher school in which individual organizational units can perform and are performing different functions (including the dominant functions in the activities of this unit).

\section{CONSEQUENCES OF UNDERSTANDING AND APPRECIATION OF HIGHER EDUCATION DIVERSE MODEL}

Everyday awareness of the diversity of an education institution as till then - is not accompanied by the attempts to find solutions that should adequately take this diversity into account. So, for example, in the universities which should be to be and largely are the environments forming knowledge, academic teachers are employed - formally speaking - to teaching classes (the raison of existence of an employee is teaching load - an adequate number of hours of classes). In contrast, the main basis is the promotion of scientific publishing output, which should be the result, among others, of study and research. In the case of education academics work in the conditions of the mass studies over the years increasingly become mainly teachers, and instead the research (especially original research on issues, important issues, conducted in representative groups) becomes the margin of their activities, they are often decoy researches, which contribute little or none to the development of science.

The system of grants serves as a support of a part of the research, first of all the research beneficial for promotion of young personnel. The vast majority of teachers, however, have scarce resources to make valuable scientific studies. A couple of generations of academic teachers are mostly involved in superficial survey research or superficial studies treated as qualitative (but usually devoid of a clear and legal theoretical and methodological basis). Research remains a neglected area of professional activity. You can clearly see the disappearance of the connections between research and teaching - the foundation of a good university education.

In this situation - not giving in to various "austerity programs" - very desirable seem to be regulations and practices based on them contributing to actual research activities, and thus, for example, periodic entrusting of research responsibilities (in place of some or all teaching duties), enforcement of the use of task study leaves, creating the conditions for research in cooperation with institutions, teams or other communities outside the education institution. The procedures for the award of grants should become more open and they should be left primarily to academic community (according to pretty good early experience of the Committee for Scientific Research, those procedures are again increasingly becoming diverge and bureaucratic and connected with administrative authorities). The allocation of funds for research should be determined not so much by unknown individual opinions of experts, but rather by the bigger teams of known and recognized specialists, competent investigators. Perhaps, the right solution would be, among others, admission of the authors of the projects to the public (environmental) discussing - in the framework of competition for grants. The resulting grant would be the basis for the high evaluation of the employee, while today "points" awarded in education institutions for grants are rather an expression of the joy of receipt of funds for research by the employee (which brings some benefit to the education institutions). Generalizing, it is required that the education institution 
worker to be, first of all, a teacher, or in education establishments there should also be used posts/scientific and research posts - permanently or temporarily assigned. For environments dealing with pedagogy past practice leads to the fact that Humbold's principle of linking research and teaching will remain a fiction, and pedagogical training at the university will less and less resemble a university, and it will become more and more a variation of a vocational school. This process deals, as it can be seen, not only with university pedagogy. On the basis of pedagogy it is, perhaps, more visible - among others, because of mass education. A major symptom is, I think, aspiration to deprive education of its humanistic identity and attributing of the discipline to the social sciences, which contradicts a centuries-old tradition and humanist pedagogy identification (Levovitski, 2007 a; Vitkovski, 2011).

The above comments referred to the selected issues defining the maintaining the university character of the education institution and education in these institutions. At the same time - even just as an example - you can indicate to the exaggeratedly equal treatment in the regulations of universities and higher vocational schools. The latter, as I tried to represent, have different dominant functions assigned to them. It does not seem sensible to move on the ground of these schools, for example, the regulations guiding the periods of employment in the defined positions. The principles of the so-called rotation of personnel - mostly justified in universities and other education institutions of university type - in vocational schools can lead to the loss of a very good team, which, for example, for some reason cannot or do not want to follow the way of scientific promotion. The usefulness of this team can be and should be shown differently than in universities. The methods for confirmation of the suitability should be outlined (taking into account, for example, methodical developments, the scope and method of vocational training of students and graduates - and other achievements in the field of vocational training, development of students' competence, collaboration with employers, etc.).

Similar cases are, of course, more numerous. I am indicating only to a clear need to take into account also the provisions regulating the activities of the university or in the practice of their education institution differentiation activities including the range of activities, dominant tasks and functions and the conditions of functioning. In the differentiation of a model of education it is becoming an important factor of successful operation and development of the education institution, university environments. This thing requires careful thinking, expert approach and a high degree of detachment from the schematic perception of higher education.

\section{THE PROBLEMS OF HIGHER EDUCATION AND (FOR CONSIDERATION) SUGGESTED SOLUTIONS}

The described phenomena - including quantitative development of education, massification of higher education, shortage of staff, reducing the quality of education, the lack of a strategic approach to matters of academic education raise many problems. After a period of vigorous creation of non-public schools it takes time to disclose the various signs of a crisis. Unclear future of many education institutions is felt more and more clearly, graduates of fashionable fields turn out to be useless in the labour market, many graduates become convinced that their 
skills do not match the employers' requirements. A threat to the future of a large part of higher education is the demographic decline and decline in the number of people taking up studies connected with it. For example starting from the academic year 2005/06 the number of students decreased by $5.8 \%$, and in the years $2009 / 10$ and 2010/11 (in one year) the decline in the number of students was $3.1 \%$ (Higher schools and their finances in 2010) but during the same year, the number of students in private schools fell by $8.4 \%$ (ibid). This trend has recently got a stable character. The provided figures illustrate the situation in all education and they also reflect the negative trend in education establishments preparing educators and teachers.

There is no improvement in the situation with the staff, as I mentioned earlier. In the case of pedagogies this situation is very worrying. Another diagnosis of the condition of the educators' community (Levovitski, 1995; 2004) provided the information about problems with reproduction (not mentioning already about the development) of staff with the highest qualifications, professors. Weak is the influx of young specialists - especially in university centres, which are usually the greatest potential for development and scientific advancement. The situation is exacerbated - firstly - by a relatively large influx into pedagogies of people representing different disciplines (military science, technical, theological sciences and others.) - people probably competent in these disciplines, but often poorly versed in the modern state of pedagogies, poorly prepared for pedagogical research and usually adding nothing original to the development of pedagogies, and, secondly, promotion obtained outside Poland (low requirements in some of the neighbouring countries make for the receipt of scientific degrees and titles there by persons without numerous scientific achievements in Poland, almost or completely unfamiliar with the achievements in the field of pedagogies) (I am writing about this in the work: Levovitski, 2007 a; 2010). Despite the argumentation quoted sometimes that is conducive to the development of interdisciplinary education, it does not bring any benefit to this discipline. This argumentation is usually an elegant rundown excuse for weakness rather than a sign of concern for the development of pedagogy. The motive of this special indulgence in recognition of educational qualifications of newcomers from other areas and disciplines are staff shortages and a desire to meet the formal requirements - as it is estimated by the - "minimum staffing" entitling them to conduct the field of studies and bestowing professional titles and sometimes - academic degrees and scientific titles. The presented state and the described phenomenon relate to almost all, and in any event, the vast majority of education institutions preparing pedagogues and teachers (those former in pedagogical fields, and others - both in pedagogical fields and, as mostly, in other fields of study) (Levovitski, 2007 b). Of course, in terms of mass education positive examples can be indicated - some universities and a few or several, perhaps dozens, of other education institutions, including private education institutions. This does not change the overall picture of the personnel a bad situation in which exceptions are encouraged.

All this obviously has negative impact on the quality of education. High quality is not encouraged by the deepening chaos in programs, alluring (but risky) wealth of books and scripts (often having a dubious educating value) or - rarely noticed (Levovitski, $2007 \mathrm{~b}$ ) -the disruption of the content structure and the logic of the educational process caused by the breakdown of studies into two stages, wherein the first degree has to be a vocational training, somewhat detailed, and the 
second has to be general (this is the reverse of the order of the contents, in which the general content should be the foundation for general vocational or specialist training content).

The list of weaknesses and problems of education in universities can be easily extended - among many distressing things which are necessary to change, for example, weakening of the ties between education and practice, treatment of education standards (program minimums) as a program of maximum, the shift (despite declarations) of the studies towards typical school forms of education. A common phenomenon is the disappearance of the elite features of education in the education institutions, disappearance of the culture-forming functions which form a stratum of social intelligence. And in these areas there are still few exceptions. General trends have emerged, however they are not very encouraging.

Politicians, state administration responsible for science and higher education, various advisers of administration see many weaknesses. Various and often misguided attempts are made to revive university environments. The efforts towards the quality of studies and academic work turn out to be phoney. An example of absurdity was a regulation stating that a text published in journals or miscellany should contain a minimum of 40 thousand typefaces to get the appropriate score - counting to the assessment of an employee and an organizational unit, and consequently giving rise, among others, to grant funds for scientific activities. This provision was modified, the number of required characters was reduced, but the peculiar logic of determining the quality of work based on the number of characters did not disappear. This is only one example of many possible. A facade concern for the quality determined and is determining the activities of agencies and various bodies - including the State Commission on Accreditation. The quality of education is determined mainly on the basis of documentation.

Understanding the weakness led the representatives of the administration to a conclusion that some education institutions (mostly private ones) will stop working in less than favourable conditions than it was before - after the end of the educational boom. It is in some sense a "free-market" approach to the problem the demand caused a spontaneous creation of education institutions, wherein very different motives accompanied their establishment (Levovitski, 2010), and now the crisis phenomena will result in liquidation - as it is assumed - of weak, useless education institutions, not coping with the conditions of educational competition. This view of the matter of higher education disseminated in the media of mass communication is becoming an expected condition.

The expected scenario is seen as very possible and very likely.

You can ask some basic questions - should we wait for the fulfillment of this scenario? Do not the educational, social and state policies have or should not have a program of targeted actions that would or could be helpful to higher education? Should not this significant number of new institutions - despite their various weaknesses - be treated as a social good, manifestation of initiatives for dissemination and education (let us repeat it, after all) bringing social benefits, revival of educational aspirations, as well as cultural impulses, and finally, also economic benefits, greater efforts of local communities towards infrastructure, encouragement to think about a better future for children and grandchildren? What roles can be assigned to education "potentates", academic communities in large agglomerations - passive observers, communities satisfied with the collapse of some competitors, or also communities involved in creating the common good, 
which is education? So we come to the heart of matters. The answers to these questions seem to be significant in understanding and in efforts for education.

The scenario quoted earlier can be interpreted as a manifestation of mostly passively waiting for the course of events. It is difficult to find evidence that there is some positive educational policy or aid programs. Another significant social effort and the possibility of its use do not seem to arouse the imagination of politicians and administration. Large state universities from the beginning of the process of establishing new higher schools treat them as competition and the source of evil in higher education. The largest education institutions took resolutions of the conflict of interests and prohibited their employees to work in "competitive" high schools. The latter were not competitors in the enrolment of students, because, as a rule, young people first apply for free studies at public universities, which are state in their essence. In the case of pedagogies academicians did not carry out from universities the secret knowledge, valuable research results - they disseminated publicly available knowledge and contributed to (or could contribute) to the training of educators and teachers at a good level. And furthermore, what was important for many, they finished working with meagre university pensions. It's true that somebody did it without moderation. Prohibitions and various annoyances made for people working in the "competitive" schools made the legalists undertook additional work in the localities "safely" away from the seats of their alma maters. So functioned and continues functioning a large group of teachers - wandering, often covering considerable distances, losing time and strength.

For these questions, however, one can and should seek other answers and manifest other behaviours. The basic should be a concern for the common good, which is education. Instead of passive waiting for - as Zorba the Greek could call it - for a "beautiful disaster" or severe, destructing crisis, it seems desirable to create legal conditions and incentives saving this good and assigning it even a greater value. Instead of rejecting such ideas, for example, merger of public and private education institutions, and only allowing joining of private education institutions, the solution promising multilateral benefit would be the creation of conditions and - incentives just to the close cooperation of large and medium-sized public education institutions with mostly small non-public schools. Education institutions such as universities should accept the scientific patronage in the field of research, care about the level of education. Extremely important would be their participation in the training of scientific personnel, creating opportunities for scientific development of teachers of smaller schools. The environments in which such schools operate are a potential area of joint research. A natural phenomenon should be the ability to work in both education institutions - with shared responsibility for the quality of work. Of course, in many environments there will be opponents, obstacles will probably be multiplied, many teachers will show dislike. The prospects of cooperation may not appeal to academic authorities settled in their posts. Well, they will remain resistant alone and they will be fighting themselves for survival. But it is important to create opportunities for the communities that will understand that this is the chance for development and mutual assistance. For large education institutions having strong personnel that will be an extraordinary opportunity to show, that the noble words recorded in the documents defining the mission of these education institutions are not empty platitudes. For small environments it will be the opportunity to get closer to the best university standards, becoming authentic academic environments. 


\section{CONCLUSIONS}

The proposed solutions are part of a diversified model of higher education, and they more accentuate the cooperation of schools - generally speaking - of different categories. Such cooperation may lead to the integration of the education institution, and this will open the academic development opportunities and foster synergies flowing from the interaction of different entities of education.

The success of this project depends, of course, on the involvement of many non-university environments - government, local authorities, and local elites. Important is the support of the media, various opinion leaders. An important factor of success may be various forms of social support, forms of civic activity.

The suggestions are an incentive for other than hitherto perception of higher education and its fate. It is an invitation to consider and take steps aimed at the development of education - the whole of higher education. This is the appeal, which probably will not probably mobilize for the actions of individuals and groups that adhere to the principle of life saying that we should not and cannot change the patterns of thought and behaviour. This appeal is directed to the communities, which are not indifferent to the condition of education and are or may be interested in protection and enhancement of social capital, achievements and development opportunities posed by higher education. This is a call for a possible imminent development of a positive program.

For decades, we have noticed the need for recognition of education for the chief priority (Education as a national priority ...). Knowledge societies have opportunities for development and successful functioning in the modern world. Will this be reflected in the Polish higher education system?

\section{REFERENCES}

1. Bashkievich, Y. (1997). Youth of universities. Warsaw: "Student” ("Żak”).

2. Buchner-Yezhyorska, A. (ed.). (2005). School success or survival? Higher education in Poland. Warsaw: School of Economics.

3. Cros, L. (1961). "L'explosion” scolaire. Paris: CUIP.

4. Development de l'education en Europe: analyse statistique. (1980). UNESCO.

5. Education as a national priority. Report on the status and development of national education in PRL. (1989). Warsaw-Krakow: PWN.

6. Kot, S. (1996). History of education. Warsaw: "Student” (“Żak”).

7. Krapiets, M. (1982). Man, culture, university. Lublin: KUL.

8. Kupishewich, C. (1978). Changes in the educational world. Warsaw: WP.

9. Kupishewich, C. (1982). Education in the process of remodeling. Directions of educational reforms in industrialized countries 1945-1980. Warsaw: WSiP.

10. Levovitski, T. (ed.). (1985). Model of diverse university. Warsaw: IPN. PTiSzW.

11. Levovitski, T. (1995). On the condition of pedagogy. KNP PAN: "Yearbook of Education".

12. Levovitski, T. (2004). Pedagogy - twenty years later (1994-2004) sketches about the condition of scientific discipline and attempts to meet the needs of society. KNP PAN: "Yearbook of Education".

13. Levovitski, T. (2007). On the identity and condition and duties of pedagogy. Warsaw-Radom: ITE. 
14. Levovitski, T. (2007). The problems of education and teachers' work. Warsaw-Radom: ITE.

15. Levovitski, T. (2010). Non-public universities in Poland. Twenty years of the operation of private universities in Poland. Krakow: Publishing House "Impulse".

16. Marek, F. (1995). The honour, dignity, and mission of the university. UO. Opole.

17. Regulska, E. (1990). Social and educational functions of open universities. Ministry of Education, Institute of Science Policy and Higher Education. WarsawLodz: PWN.

18. Statistical Yearbook. Central Statistical Office (1992). Warsaw.

19. Struzhevski, V. (1992). In the sphere of values. Krakow: "Znak".

20. Shchepanski, Y. (1963). Sociological aspects of higher education. Warsaw: PWN.

21. Shchepanski, Y. (1976). Essays on Higher Education. Warsaw: WP.

22. Shgerlag, A. (ed.). (2006). Problems of education in high school. Krakow: Publishing House "Impulse".

23. Higher schools and their finances in 2008. Central Statistical Office. (2009). Warsaw.

24. Higher schools and their finances in 2010. Central Statistical Office. (2011). Warsaw.

25. Touraine, A. (1979). The end of the transformation of the universities? Modernity in education and upbringing. Warsaw: WSiP.

26. Vitkovski, L. (2007). Education and humanities: new (con) texts for modern teachers. Warsaw: IBE.

27. Vitkovski, L. (2011). Obstacles to the development of the humanities in higher education (pedagogy in the background) in the perspective of care. Torun.

28. Voloshyn, S. (1964). Sources for the history of education and pedagogical thought. Warsaw: PWN, 1.

29. Znanetski, F. (1984). The social role of scholars. Choice, introduction, translation. Warsaw: PWN. 